\title{
LA DIVULGACIÓN DE LA INVESTIGACIÓN CIENTÍFICA
}

En el mundo contemporáneo las naciones están en constante competencia, pues los avances de la tecnología provocan continuamente cambios que inciden en los más diversos ámbitos de la vida cotidiana. Pero la ciencia no puede ser cerrada y excluyente, tiene que ser compartida.

En la época contemporánea, la publicación de revistas científicas constituye un elemento fundamental para la divulgación de los resultados de las investigaciones en las diversas ramas de la ciencia, para el debate, conocimiento y aplicación de los mismos.

El conocimiento científico en tiempos remotos era divulgado en círculos muy pequeños, pues los medios de comunicación estaban poco desarrollados. Los avances en la trasmisión de los mismos, permitieron una mayor amplitud que potenció el desarrollo de los diversos ámbitos de las actividades humanas.

Durante siglos, la información era en círculos cerrados y tardaba muchos años en su propagación. Pero el motor del progreso ha estado ligado al compartimiento de los saberes. La creación de las Universidades a finales de la Edad Media, significó un paso importante para la trasmisión y discusión de los temas científicos. La aparición de la imprenta en el Renacimiento produjo un intercambio mayor en la comunidad científica. En la era Moderna la inclusión ocasional de artículos científicos en los primeros periódicos, permitió por primera vez una masificación del conocimiento. Ya en la era Contemporánea, los avances tecnológicos como la radio y posteriormente la televisión, dieron nuevas oportunidades de difusión. Pero la vorágine de información y la trivialidad en los medios de mayor expansión, derivó en la aparición de las publicaciones exclusivamente científicas, con especialización dedicada a una comunidad específica.

La Universidad moderna cuenta con una o más publicaciones científicas, en las que se exponen los resultados de investigadores propios, así como las colaboraciones de académicos externos como parte de un intercambio con otros centros de investigación del país y del exterior. La ciencia no tiene fronteras y mientras más amplio es el espectro discusión, mayor es el nivel que alcanzan las investigaciones.

La revista Alternativas es una de las publicaciones científicas de la Universidad Católica de Santiago de Guayaquil. Nos encontramos en un proceso de renovación continua y nos es grato publicar en este número artículos de nuestros docentes y de profesionales de otras instituciones. Este aporte bibliográfico será de utilidad en el concierto profesional por su contenido amplio sobre temas de palpitante actualidad.

Econ. Mauro Toscanini Segale, MBA. MSc. 